\title{
COMPARISON OF EFFICACY OF SEMONTS MANOEUVRE VERSUS VESTIBULAR SEDDATIVE IN POSITIONAL VERTIGO
}

\author{
Muhammad Sohail Babar Niazi, Khawar Kamal*, Zaheer Ul Hassan, Aisha Qaiser**, Shahid Farooq Khattak, Shahid Iqbal* \\ Combined Military Hospital Peshawar/National University of Medical Sciences (NUMS) Pakistan, *Combined Military Hospital Gujranwala/National University \\ of Medical Sciences (NUMS) Pakistan, **Fauji Foundation Hospital, Peshawar Pakistan
}

\begin{abstract}
Objective: To carry out the comparison of the effectiveness of Semont manoeuvre and Vestibular Sedative in the management of benign paroxysmal positional vertigo (BPPV).

Study Design: Quasi experimental study.

Place and Duration of Study: Department of ENT, Combined Military Hospital Peshawar Pakistan, from Jan to Jul 2020. Methodology: The study was conducted on 60 patients who were diagnosed Benign Paroxysmal Positional Vertigo by Dix Hallpike test. The patients were divided into 2 groups of 30 each. Group A was treated with vestibular sedative and group B was treated with Semont manoeuvre. The examination of all patients was done on day 3, day 7 and day 14 and the results were documented.

Results: The study was conducted on 60 patients who were diagnosed benign paroxysmal positional vertigo by Dix Hallpike test the study revealed that the 30 cases which were treated by Semont manoeuvre, 25 cases were completely symptom free after 14 days. Meanwhile out of 30 cases which were managed by oral vestibular sedative, only 4 cases showed complete recovery after 14 days. Chi square test was used to compare the results. The results revealed that Semont manoeuvre is more effective in the treatment of benign paroxysmal positional vertigo than vestibular sedative.

Conclusion: Semont manoeuvre is more effective in the management of benign paroxysmal positional vertigo than vestibular sedative.
\end{abstract}

Keywords: Benign paroxysmal positional vertigo, Semont Manoeuvre, Vestibular sedative.

How to Cite This Article: Niazi MSB, Kamal K, Hassan ZU, Qaiser A, Khattak SF, Iqbal S. Comparison of Efficacy of Semonts Manoeuvre Versus Vestibular Seddative in Positional Vertigo. Pak Armed Forces Med J 2021; 71 (Suppl-3): S539-541. Doi: https://doi.org/10.51253/pafmj.v1i1.7929

This is an Open Access article distributed under the terms of the Creative Commons Attribution License (https://creativecommons.org/licenses/by-nc/4.0/), which permits unrestricted use, distribution, and reproduction in any medium, provided the original work is properly cited.

\section{INTRODUCTION}

Benign Paroxysmal Positional Vertigo (BPPV) represents a condition resulting from a pathology in the inner ear (saccule, utricle and semicircular canals). ${ }^{1}$ The classical episode consists of repeated and brief periods of vertigo associated with movements of the head. The vertigo is characterized a spinning sensation resulting from the changes in the head posture. ${ }^{2}$ It occurs with either turning side in bed or changing the position of head while looking or turning up. A single episode of vertigo typically lasts for a few seconds. It can be accompanied with nausea and vomiting. BPPV is one of the most common causes of vertigo after labyrinthitis and Meniers disease. ${ }^{3}$ BPPV also occurs after head injury due to dislodgment of otoconia from the saccule into the semicircular canals or it may simply be associated with old age. ${ }^{3}$ Diagnosis is confirmed when the DixHallpike test results in nystagmus. ${ }^{4}$ The Semont manoeuvre is carried out to treat BPPV. ${ }^{5}$ The manoeuvre is designed to reposition the displaced otolith back into the saccule and utricle from the posterior semicircular canals.

Correspondence: Dr Muhammad Sohail Babar Niazi, Pathology Department, Fauji Foundation Hospital Peshawar Pakistan

\section{METHODOLOGY}

This quasi experimental study was conducted in ENT Department, Combined Military Hospital Peshawar Pakistan, from January to July 2020.

Inclusion Criteria: All patients of BPPV diagnosed positive by Dix Hall pike test.

Exclusion Criteria: Neck trauma in last 3 months Diagnosed case of cervical spondylosis.

Proper consent was taken from the hospital ethics committee before the start of the study. All the patients in the study were included after complete informed consent. Detailed history was taken about the onset and duration of vertigo along with associated symptoms. The Dix Hall pike manoeuvre was used as the standard test for the confirmation of BPPV. The patients were divided into two groups by employing the random number Tables. The patients in group A were managed by giving them per orally tab prochloperazine maleate (stemetil) $5 \mathrm{mg} 8$ hourly daily for 14 days.

Semont manoeuvre was used for the treatment of patients in group B. This manoeuvre started with the patient sitting upright on a bed or couch. After that the head of the patient was turned 45 degrees horizontally 
toward the unaffected ear. Following it while maintaining the head position, the patient was laid sideways. This position was held for 30 seconds after stop of dizziness. Then the patient was moved briskly via the sitting position, keeping his head in position till he lied on the normal ear's side. In this posture the nose of the patient pointed 45 degree towards the floor. This position was held for 30 seconds after stop of dizziness. After this he was slowly moved back to the seated posture while looking straight forward. He remained in this posture for three minutes The examination of all patients was done on day 3, day 7 and day 14 and the results were documented.

\section{Data Analysis}

All data was analyzed on statistical package for social sciences (SPSS) version 20. Age and gender were the variables which were put to analysis. For the numerical data the calculation of mean and standard deviation was performed while frequency \& percentage were employed for data regarding relief from vertigo. The two groups were compared by using chi square test owing to the qualitative nature of the data. The significance level of $p$-value was considered as $\leq 0.05$.

\section{RESULTS}

Group A was treated with oral vestibular sedative. On the $3^{\text {rd }}$ day only 1 patient got relief from vertigo and showed negative Dix Hallpike test. On day, ${ }^{7}$ the DixHallpike test became negative for vertigo and nystagmus in further 2 patients. Finally on the day 14, 4 patients out of 30 had negative Dix Hallpike test showing relief from vertigo and nystagmus.

Semont manoeuvre was used for the treatment of patients in group B. At the $3^{\text {rd }}$ day 22 patients got relief from symptoms and Dix Hallpike test became negative. At the $7^{\text {th }}$ day same development was observed for further 5 patients. Finally on day 14, 29 patients from a group of 30 got relief from symptoms and showed negative Dix Hallpike test. Chi square test was employed for the comparison of the two groups. The calculation of $p$-value was done. It showed to be less than 0.05 on all days of the study. Therefore the conclusion was made that the Semont manoeuvre is more effective as compared to vestibular sedative in treating BPPV. The comparison of both the groups on day 7 has been shown in Figure-1. Figure-2 and Table shows the comparison of both groups on day. ${ }^{14}$

In group A of oral sedative 12 were females while 18 were males. In group B (Semont group) 10 were females while 20 were males. The range of the age was from 25-75 years with a mean age incidence of 40.15 years and a standard deviation of 6.95. In group B, 5 patients $(16.6 \%)$ had feeling of nausea during the Semont manoeuvre. Two patients $(6.6 \%)$ had deafness and 3 patients (10\%) had tinnitus in group A while 1 patient $(3.3 \%)$ had deafness and 1 patient $(3.3 \%)$ had tinnitus in the group B.

Table: Treatment outcome on day 14.

\begin{tabular}{|c|c|c|c|}
\hline \multirow[b]{2}{*}{$n=60$} & \multicolumn{2}{|c|}{ Dix Hallpike Test } & \\
\hline & $\begin{array}{c}\text { Negative (Relief } \\
\text { from vertigo and } \\
\text { nystagmus) }\end{array}$ & $\begin{array}{c}\text { Positive (No relief } \\
\text { from vertigo and } \\
\text { nystagmus) }\end{array}$ & \\
\hline $\begin{array}{l}\text { Group A } \\
\text { (Oral Sedative) }\end{array}$ & $4(13.3 \%)$ & $26(86.6 \%)$ & 30 \\
\hline $\begin{array}{l}\text { Group B (Semont } \\
\text { Manoeuvre) }\end{array}$ & $29(96.6 \%)$ & $1(3.3 \%)$ & 30 \\
\hline
\end{tabular}

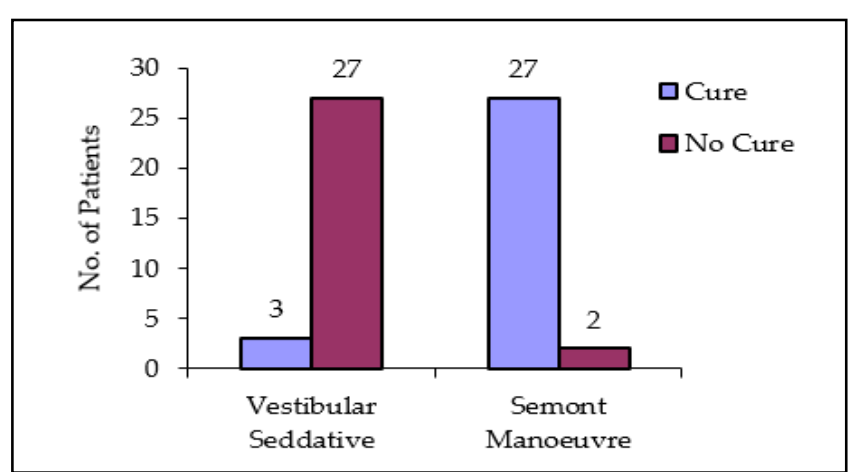

Figure-1: Outcome of vestibular sedative and epleys manoeuvre after 7 days $(n=60)$.

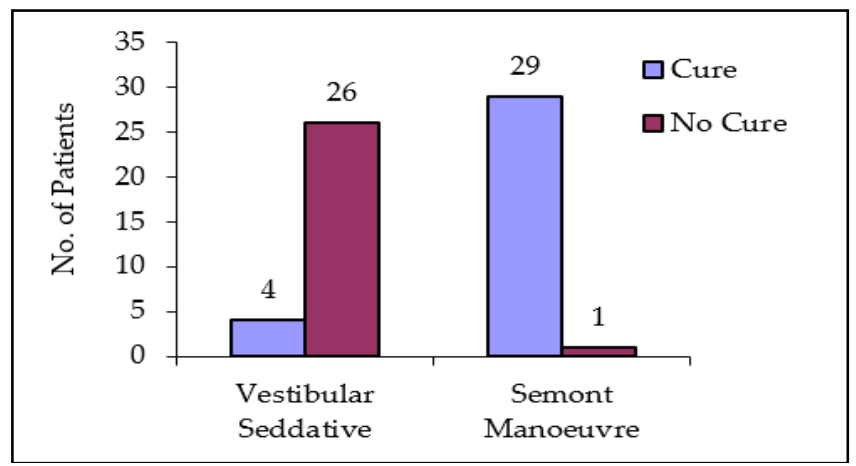

Figure-2: Outcome of vestibular sedative and epleys manoeuvre after 14 days $(n=60)$.

\section{DISCUSSION}

Vertigo is a very common disorder among various population groups all over the world. BPPV is a frequent problem encountered by clinicians in the outdoor patient department. Once properly diagnosed it can be cured by various canal repositioning manoeuvres. Semont manoeuvre is one of the possible treatment options for this condition.

Gupta et $a l^{6}$ conducted a study regarding the role of Semont manoeuvre in the management of BPPV 
which showed very high cure rates by the manoeuvre. It also established the role of Semont manoeuvre and other canalith repositioning manoeuvres in the remarkable improvement in the quality of life of the patients of BPPV. Gans RE 7 conducted a very comprehensive study on the 376 patients of BPPV. He along with his colleagues found that the Semont liberatory manoeuvre is highly effective in the management of BPPV. Moreover one huge advantage of this manoeuvre that the manoeuvre can also be carried out at home by the patient himself without the help of any other person.

Another comparative prospective study on the efficacy of Semont manoeuvre was conducted by Salvinelli et $a l^{8}$ which showed similar results to our study regarding the effectiveness of Semont manoeuvre in BPPV. Frevss et $a l^{9}$ revealed that $85 \%$ of the patients suffering from BPPV were cured by employing the Semont manoeuvre. Excellent treatment outcome of BPPV was observed by Naimatullah while employing the Semont manoeuvre. ${ }^{10}$ A local study conducted in Pakistan showed the high efficacy of Semont manoeuvre in the treatment of BPPV. ${ }^{11}$ There have been a few studies which have employed all different types of manoeuvres in the management of BPPV and they have shown the high cure rate of Semont manoeuvre in BPPV. ${ }^{12-15}$ Various vestibular sedatives have been employed in several cases of severe vertigo. ${ }^{16}$ They decrease the severity of vertigo and nystagmus by masking the vestibular system. Conventional vestibular suppressants consist of three major drug groups: anti-cholinergics, antihistamines and benzodiazepines. ${ }^{17,18}$ In our study we were unable to get satisfactory results for resolution of vertigo from the use of vestibular sedatives.

\section{CONCLUSION}

Semont manoeuvre is more effective in the treatment of BPPV than vestibular sedative.

Conflict of Interest: None.

\section{Authors' Contribution}

M MSBN: Conceived the main idea, developed study design, KK: Statistical analysis, ZUH: Manuscipt drafting and bibliography, AQ: Helped in data interpratation, SFK: Research supervisor, SI: Developed study tool, literature survey.

\section{REFERENCES}

1. Hotson JR, Baloh RW. Acute vestibular syndrome. N Engl J Med 1998; 339(2): 680-685.
2. Furman JM, Cass SP. Benign paroxysmal positional vertigo. $\mathrm{N}$ Engl J Med 1999; 341(1): 1590-1596.

3. Von M, Radtke A, Lezius F. Epidemiology of benign paroxysmal positional vertigo: a population based study. J Neurol Neur Psych 2007; 78(1): 710-715.

4. Kahraman SS, Yildirim YS, Tugrul S. Repositioning intervals in the modified Epley's maneuver and their effect on benign paroxysmal positional vertigo treatment outcome. Acta Otolaryngol 2017; 137(2): 490-494.

5. Alghwiri AA, Whitney SL, Baker CE, Sparto PJ, Marchetti GF, Rogers JC, et al. The development and validation of the vestibular activities and participation measure. Arch Phys Med Rehabil 2012; 93(1): 1822-1831.

6. Gupta A, Sharma K. Effect of Epley, Semont Maneu-vers and brandt-daroff exercise on quality of life in patients with posterior semicircular canal benign paroxysmal positional vertigo (PSCBPPV). Ind J Otolaryngol Head Neck Surg 2019; 71: 99-103.

7. Gans RE, Harrington-Gans PA. Treatment efficacy of benign paroxysmal positional vertigo (BVVP) with canalith repositio-ning maneuver and Semont liberatory maneuver in 376 patients. Semin Hear 2002; 23(2): 129-142.

8. Salvinelli F, Casale M, Trivelli M, D'Ascanioo L, Firrisi L, Lamanna $\mathrm{F}$, et al. Benign paroxysmal positional vertigo: a comparative prospective study on the efficacy of semonts maneuver and no treatment strategy. Clin Ter 2003; 11(1): 154-157.

9. Semont A, Freyss G, Vitte E. Curing the BPPV with a liberatory manoeuvre. Adv Otorhinolaryngol 1988; 42(2): 290-293.

10. Naimatullah, Yousaf N. Single treatment approaches to benign paroxysmal positional vertigo. Pak J Otolaryngol 2004; 20(1): 3-5.

11. Mazoor T, Niazi SB. Efficacy of semont manoeuvre versus epley manoeuvre in benign paroxysmal positional. Pak Armed For Med J 2011; 61(2): 70-73.

12. Gupta AK. Effect of Epley, Semont maneuvers and brandt-daroff exercise on quality of life in patients with posterior semicircular canal benign paroxysmal positional vertigo (PSCBPPV). Ind J Otolaryngol Head Neck Surg 2019; 71(2): 99-103.

13. Zhang YX, Wu CL, Xiao GR, Zhong FF. Zhang YX. Comparison of three types of self-treatments for posterior canal benign paroxysmal positional vertigo: modified Epley maneuver, modified Semont maneuver and Brandt-Daroff maneuver. Zhonghua Er Bi Yan Hou Tou Jing Wai Ke Za Zhi 2012; 47(1): 799-803.

14. Sinsamutpadung C, Kulthaveesup A. Sinsamutpadung C. Comparison of outcomes of the epley and semont maneuvers in posterior canal BPPV: a randomized controlled trial. Laryngoscope Investig Otolaryngol 2021; 6(2): 866-871.

15. Gebhart I, Götting C, Hool SL, Morrison M, Korda A, Caversaccio $\mathrm{M}$, et al. sémont maneuver for benign paroxysmal positional vertigo treatment: moving in the correct plane matters. Otol Neurotol 2021; 42(1): 341-34.

16. Von BM, Radtke A, Lezius F, Feldmann M, Ziese T, Lempert T, et al. Epidemiology of benign paroxysmal positional vertigo: a population based study. J Neurol Neur Psych 2007; 78(4): 710-715.

17. Kerber KA. Benign paroxysmal positional vertigo: opportunities squandered. Annals New York Acad Scien 2015; 1343(2): 106-112.

18. Beynon GJ. A review of management of benign paroxysmal positional vertigo by exercise therapy and by repositioning manoeuvres. Br J Audiol 1997; 31:11-26. 